\title{
Changes in the nutritional quality of fast-food items marketed at restaurants, 2010 v. 2013
}

\author{
Jackie Soo ${ }^{1, *}$, Jennifer L Harris ${ }^{2}$, Kirsten K Davison ${ }^{3}$, David R Williams ${ }^{1}$ and \\ Christina A Roberto ${ }^{4}$ \\ 'Department of Social and Behavioral Sciences, Harvard T.H. Chan School of Public Health, 677 Huntington \\ Avenue, Boston, MA 02115, USA: ${ }^{2}$ Rudd Center for Food Policy \& Obesity, University of Connecticut, Hartford, \\ CT, USA: ${ }^{3}$ Department of Nutrition, Harvard T.H. Chan School of Public Health, Boston, MA, USA: ${ }^{4}$ Department of \\ Medical Ethics \& Health Policy, Perelman School of Medicine, University of Pennsylvania, Philadelphia, PA, USA
}

Submitted 8 February 2017: Final revision received 18 January 2018: Accepted 20 February 2018: First published online 27 March 2018

\begin{abstract}
Objective: To examine the nutritional quality of menu items promoted in four (US) fast-food restaurant chains (McDonald's, Burger King, Wendy's, Taco Bell) in 2010 and 2013.

Design: Menu items pictured on signs and menu boards were recorded at 400 fast-food restaurants across the USA. The Nutrient Profile Index (NPI) was used to calculate overall nutrition scores for items (higher scores indicate greater nutritional quality) and was dichotomized to denote healthier $v$. less healthy items. Changes over time in NPI scores and energy of promoted foods and beverages were analysed using linear regression.

Setting: Four hundred fast-food restaurants (McDonald's, Burger King, Wendy's, Taco Bell; 100 locations per chain).

Subjects: NPI of fast-food items marketed at fast-food restaurants.

Results: Promoted foods and beverages on general menu boards and signs remained below the 'healthier' cut-off at both time points. On general menu boards, pictured items became modestly healthier from 2010 to 2013, increasing (mean (SE)) by $3.08(0.16)$ NPI score points $(P<0.001)$ and decreasing (mean (SE)) by $130(15) \mathrm{kJ}(31.1(3.65) \mathrm{kcal} ; P<0 \cdot 001)$. This pattern was evident in all chains except Taco Bell, where pictured items increased in energy. Foods and beverages pictured on the kids' section showed the greatest nutritional improvements. Although promoted foods on general menu boards and signs improved in nutritional quality, beverages remained the same or became worse.

Conclusions: Foods, and to a lesser extent, beverages, promoted on menu boards and signs in fast-food restaurants showed limited improvements in nutritional quality in 2013 v. 2010.
\end{abstract}

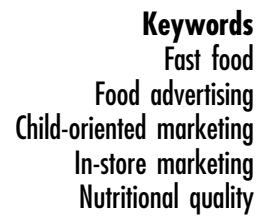

Keywords Food advertising Nutritional quality
Obesity and poor diet quality are major public health concerns and the increase in food consumption outside the home is a major contributor ${ }^{(1)}$. Nearly half of all food dollars are spent on food eaten away from home ${ }^{(2)}$ and fast-food consumption is linked to weight gain and poor diet quality ${ }^{(3-5)}$. The fast-food industry spends \$US 4.6 billion per year on advertisements and exposure to such advertising is associated with greater fast-food consumption $^{(6-8)}$. Food marketing has been identified as one of many factors that promotes overconsumption of nutritionally poor foods and poor diet quality ${ }^{(9-11)}$. Childtargeted food marketing is particularly concerning because young children do not have the cognitive capacity to distinguish between advertisements and other media content $^{(12)}$. Child-targeted advertising has also been shown to influence children's food preferences and consumption $^{(13-16)}$.

Most studies on the effects of food marketing have focused on television advertisements ${ }^{(17,18)}$, with less attention paid to marketing that occurs in or around restaurants. Marketing strategies at restaurants, such as signs, pictures and promotions to encourage sales of certain menu items ${ }^{(6)}$, can draw consumer attention to featured products ${ }^{(19-21)}$. Unfortunately, the majority of such marketing promotes unhealthy foods. One study from 2010 found that $75 \%$ of menu items featured on signs in (US) fast-food restaurants were of poor nutritional quality. Energy-dense, nutritionally poor foods were especially common on signs with value messages and price promotions $^{(6)}$. 
Although these data paint a dreary picture of fast-food marketing at restaurants, many chains have made some efforts to offer and encourage healthier food choices. In September 2012, McDonald's started posting energy (calorie) information on menus nationwide to enable nutrition-minded choices ${ }^{(22)}$. Also in 2012, Burger King added foods like salads and fruit smoothies to its menu ${ }^{(23)}$. In 2011, the National Restaurant Association launched Kids LiveWell, a voluntary programme to offer and promote at least one kids' meal that meets the programme's nutrition criteria $^{(24)}$. Another voluntary, self-regulatory programme is the Children's Food and Beverage Advertising Initiative (CFBAI), which began in 2006 and aims to improve the quality of foods advertised to children ${ }^{(25)}$. Eighteen US food and beverage companies participate in the CFBAI, including Burger King and McDonald's.

Although these strategies may signal positive changes in the food marketing landscape, they have been criticized by public health advocates for being subject to only minimal regulation and for not being sufficiently stringent $^{(26)}$. The restaurant industry has also taken simultaneous actions to thwart efforts regulating toy giveaways with children's meals not meeting certain nutritional standards $^{(27)}$, despite evidence that such policies may encourage children to select healthier meals at fast-food restaurants ${ }^{(28)}$. Given the various restaurant initiatives to offer and promote healthier foods, studies are needed to determine whether there has been systematic improvement in restaurant-industry food marketing. The aims of the current study were to examine changes from 2010 to 2013 in the nutritional quality of foods and beverages marketed at four popular fast-food chain restaurants throughout the USA. To designate marketed items, the study focused on foods and beverages that were pictured on general menu boards, pictured on the kids' section of menu boards and featured on signs inside and on the exterior of restaurants. Such pictures and signs highlight items that restaurants are actively promoting, and can serve as salient visual cues that attract attention and are likely to influence consumers, especially during quick ordering decisions ${ }^{(29)}$.

\section{Methods}

\section{Sample}

An audit of menu boards and signs was conducted in the four fast-food restaurant chains with the highest sales revenues in the USA based on Nielsen data (excluding Starbucks, considered a coffee/doughnut retail shop instead of a restaurant, and Subway, whose customizable sandwiches with varying nutrition profiles prevented them from being included in the present study) ${ }^{(30)}$. Data were collected from Burger King, McDonald's, Taco Bell and Wendy's in repeated cross-sectional samples at two time points in June 2010 and July 2013. Major market areas across the USA, defined as metropolitan statistical areas established by the federal Office of Management and Budget and used by the US Census Bureau, were selected to provide wide geographic dispersion across the country. Thirty-seven areas were selected in 2010 and twenty-one in 2013. Within each market area, individual stores from each chain were selected randomly from restaurant lists. One hundred stores were audited from each fast-food chain per year, for 400 total stores (a random sample of different stores was sampled at each year).

\section{Data collection}

A market research firm specializing in retail research conducted the audits using its national network of experienced field personnel. Field personnel underwent training in audit procedures and received a comprehensive field form together with detailed instructions. In addition to training field personnel, supervisors conducted quality control steps to ensure the collection of accurate data, including spot-checking the original data collection to check for implausible values and re-checking data within restaurants when necessary. Field forms were customized by restaurant and listed individual menu items compiled from each restaurant's online menus. For example, the field form for McDonald's listed the 'Big Mac' and other associated hamburger names, while the field form for Burger King listed the 'Whopper'. The form also provided space to write in any individual menu items that were not listed on the field form.

Marketed items at restaurants were defined as foods and beverages pictured on menu boards or featured (either with or without a picture) on signs. For each menu item at each restaurant, field personnel first recorded whether the item was pictured on menu boards inside the restaurant. Menu boards were divided into general menu boards or the kids' section of menu boards, and pictured items were coded separately within each category. The kids' section of menu boards, usually labelled as such, included kid-size meals typically sold with a side and drink, which often came with a toy or prize.

Field personnel then recorded whether each item was featured on signs, either with or without a picture. Auditors looked for signs in three locations: (i) inside the restaurant (including the counter area and all other indoor areas); (ii) at the drive-through (including signs in the drive-through lane and immediately around the outdoor menu board); and (iii) outside the restaurant (including the parking lot, main marquee sign, roof, ground, and restaurant windows facing outside). Signs included anything considered temporary or changeable and not part of the permanent menu board.

On both menu boards and signs, if menu items were pictured in a group or bundled together (such as those for value meals), each item was coded individually. For analysis, menu items were grouped into either foods (which included dessert drinks such as milkshakes or smoothies) or beverages. 


\section{Primary outcomes: nutritional quality and energy of marketed foods}

In January 2010 and February 2013, university research personnel accessed the menus posted on each restaurant's website. Each restaurant's website provided a pdf listing of all menu items and comprehensive nutrition information, including energy, fat, saturated fat, trans fat, sodium, protein and fibre per menu item or serving. The two primary outcomes were average nutritional quality and energy of menu items pictured on menu boards and featured on signs. A nutrition score was calculated for all food and beverage items using the Nutrient Profile Index (NPI). The NPI is based on the Nutrient Profiling Model used in the UK to identify foods that can be advertised to children on television ${ }^{(31)}$. This model was developed by academic researchers at the University of Oxford ${ }^{(31)}$, has been validated against ratings made by professional nutritionists $^{(32)}$ and has been used in previous US-based research to assess nutritional quality ${ }^{(33)}$. It yields a continuous score from -15 (healthier) to +34 (less healthy). The score is standardized for portion size and takes account of energy, sodium, saturated fat, sugar, protein and fibre.

For ease of interpretation and following prior research $^{(6,26,33)}$, a re-scaled NPI score was created for each item using the following formula: NPI score $=(-2) \times$ Nutrient Profiling Model score +70 . This re-calculation produces continuous NPI scores ranging from 0 (poorest nutritional quality) to 100 (highest nutritional quality). To provide context for interpreting these scores, examples include: forty-six for vanilla ice cream, fifty-eight for fruit and nut cereal bars, sixty for canned tomato soup, sixty-six for raspberry and cranberry juice, and seventy for fruit cream cheese spread $^{(34)}$.

Also consistent with other papers ${ }^{(6,33)}$, this score was dichotomized to identify 'healthier' $v$. 'less healthy' items based on the cut-offs used in the UK to determine products that can be advertised to children: $\geq 64$ for foods and $\geq 70$ for beverages. Examples of foods that meet the 'healthier' cut-off and are allowed to be advertised to children include whole-wheat bread, fresh fruit, most nuts, chicken breast, and muesli and whole-wheat cereal with no added sugar. Examples of foods that do not meet the 'healthier' cut-off include cookies, most sausages and burgers, French fries, peanut butter, and most breakfast cereals that contain added sugar ${ }^{(35)}$.

If an item had more than one size (e.g. beverages and sides such as French fries), energy information was taken from the medium size across all chains to ensure comparability.

\section{Statistical analyses}

Separate linear regressions were conducted to examine changes from 2010 to 2013 in the NPI scores and total energy of foods and beverages pictured on general menu boards, pictured on the kids' section of menu boards and featured on signs displayed at restaurants. The first model examined changes in nutritional quality and energy of items pictured on menu boards and featured on signs by including time as a binary predictor variable. To adjust for possible nutritional differences between companies or types of foods, the second model repeated this analysis controlling for restaurant chain (McDonald's, Burger King, Wendy's, Taco Bell) and whether an item was a food or beverage. To examine whether the nutritional quality of featured foods changed differentially over time compared with beverages, a third model included time, restaurant chain and food or beverage as covariates, along with an interaction term between time and food or beverage. Significant interactions were probed further with separate regression analyses within foods and within beverages to better understand the nature of the interaction. To assess whether overall patterns held within the different restaurant chains, these analyses were then repeated within each chain. For all analyses, menu items that appeared within the same individual store were clustered and regression with robust variance was used to account for such correlations in promotion that may occur within each store. Taco Bell was excluded from analysis of the kids' section of menu boards because it discontinued its kids' menu in 2013 before data collection.

As a secondary analysis, NPI scores and energy for items pictured on menu boards and featured on signs were compared among chains in 2013 only using linear regression. These models included chain as an independent variable and controlled for food or beverage. Regression with robust variance was also used to examine changes in the proportions of 'healthier' featured foods and beverages in 2013 compared with 2010. To classify foods as 'healthier' or 'less healthy,' the specified NPI cut-offs were used, as done in prior research ${ }^{(33)}$. Since these cut-offs are defined differently for foods and beverages, these analyses did not control for food or beverage. Analyses were conducted separately for items pictured on general menu boards, pictured on the kids' section of menu boards and featured on signs, and were conducted overall, controlling for chain, as well as separately for each chain.

Prior to conducting analyses, missing data were assessed. Less than $10 \%$ of data for each restaurant had missing nutritional information in the menu boards analysis (McDonald's, 0.12\%; Burger King, 5.00\%; Wendy's, $8.25 \%$; Taco Bell, 5.09\%). Items were missing nutrition information if they were not listed on the restaurant's website, usually because they were regional products, tests or new products, or discontinued products. An examination of the distribution of food and beverage categories in missing data compared with the distribution in non-missing data revealed that nutritional data were more likely to be missing for desserts at McDonald's, Burger King and Wendy's, for coffee beverages at Burger King, and for lunch and dinner sides at Taco Bell. In the sign analysis, over $20 \%$ of the menu items from Wendy's 
and Taco Bell were missing nutritional information, probably because items on signs were more likely to be newer or available for a limited time or in certain regions. Since the missing information could bias results, the final sign analysis included only McDonald's (1.24\% missing data) and Burger King ( $4.91 \%$ missing data). All analyses were conducted with the SAS statistical software package version 9.4.

\section{Results}

\section{Overall NPI scores in 2010}

In 2010, overall mean NPI score was $53 \cdot 3$ (se 0.2) for foods and 68.7 ( $\mathrm{se} 0 \cdot 1)$ for beverages pictured on general menu boards, both of which were below the cut-off for 'healthier' items allowed to be advertised to children in the UK. Mean NPI scores for items featured on signage were similar, at 47.9 (SE 0.3) for foods and 69.2 (SE 0.1) for beverages. Mean NPI scores for items pictured on the kids' section of menu boards were somewhat higher, at 55.5 (SE 0.5) for foods and 70.6 (sE 0.1) for beverages. The latter score of 70.6 indicated an average score for pictured beverages that was in the 'healthier' category.

\section{Changes in nutritional quality of marketed items across restaurant chains}

Changes over time in the nutritional quality of featured items across all four chains are shown in Table 1 and changes broken down by restaurant chain are shown in
Tables 2-4. Figure 1 shows changes from 2010 to 2013 in unadjusted mean NPI scores and total energy by chain for items featured on general menu boards, the kids' section of menu boards and signs.

\section{General menu boards}

Across chains, pictured menu board items became healthier over time based on significant increases in mean NPI scores and decreases in mean energy after adjusting for food or beverage category and restaurant chain (Table 1). Moreover, the interaction between time and food or beverage was significant for both NPI scores and energy $(P<0.001)$. Foods, which made up a larger proportion of pictured items than beverages, improved in both NPI scores and energy $(P<0.001)$ over time; however, pictured beverages became significantly less healthy, decreasing in NPI scores and increasing in energy $(P<0.001)$. Although foods improved in NPI scores, their mean score in $2013(57 \cdot 7$ (SE 0.2)) was still below the cut-off designating 'healthier' foods.

An identical pattern of results was observed for McDonald's and Burger King (Tables 2 and 3). Wendy's (Table 4) had a similar pattern of results, except that rather than declining in nutritional value, pictured beverages did not change on either outcome $(P=0.822$ for NPI scores and $P=0.397$ for energy). For Taco Bell (Table 4), pictured items on menu boards became healthier based on NPI scores, but also increased in energy in adjusted analyses. Both pictured foods and beverages increased in energy.

Table 1 Linear regression showing changes in mean Nutrient Profile Index (NPI) scores and total energy from 2010 to 2013 for foods and beverages marketed on menu boards and signs, averaged across four major (US) fast-food chains (100 locations per chain)

\begin{tabular}{|c|c|c|c|c|c|c|c|c|c|c|c|c|c|c|c|c|}
\hline & \multicolumn{8}{|c|}{ NPI scores } & \multicolumn{8}{|c|}{ Total energy (kcal) } \\
\hline & \multicolumn{6}{|c|}{ Unadjusted } & & & \multicolumn{6}{|c|}{ Unadjusted } & \multirow{2}{*}{\multicolumn{2}{|c|}{ Adjusted }} \\
\hline & \multicolumn{2}{|c|}{$N+$} & \multicolumn{2}{|c|}{2010} & \multicolumn{2}{|c|}{2013} & \multicolumn{2}{|l|}{ Adjusted } & \multicolumn{2}{|c|}{$N+, \ddagger$} & \multicolumn{2}{|c|}{2010} & \multicolumn{2}{|c|}{2013} & & \\
\hline & 2010 & 2013 & Mean & $\mathrm{SE}$ & Mean & SE & $\begin{array}{c}\text { Mean } \\
\text { difference }\end{array}$ & SE & 2010 & 2013 & 3 Mean & SE & Mean & SE & $\begin{array}{c}\text { Mean } \\
\text { difference }\end{array}$ & SE \\
\hline \multicolumn{17}{|c|}{ General menu boards } \\
\hline Total§ & 7558 & 7447 & $55 \cdot 6$ & 0.1 & $59 \cdot 2^{*}$ & 0.1 & $3 \cdot 1^{*}, \mathbb{\prod}$ & 0.2 & 7596 & 7578 & $463 \cdot 1$ & 3.0 & $417 \cdot 3^{*}$ & 2.5 & $-31 \cdot 1^{\star}, \mathbb{\prod}$ & 3.7 \\
\hline Foods $\|$ & 6438 & 6261 & $53 \cdot 3$ & 0.2 & $57 \cdot 7^{*}$ & 0.2 & $3 \cdot 8^{*}$ & 0.2 & 6476 & 6319 & 518.6 & 2.9 & $461 \cdot 2^{*}$ & 2.5 & $-45 \cdot 2^{*}$ & 4.3 \\
\hline Beverages $\|$ & 1120 & 1186 & $68 \cdot 7$ & 0.1 & $67 \cdot 3^{*}$ & 0.1 & $-1 \cdot 3^{*}$ & 0.1 & 1120 & 1259 & $142 \cdot 3$ & 3.3 & $197 \cdot 2^{*}$ & $4 \cdot 3$ & $54 \cdot 8^{*}$ & 3.8 \\
\hline \multicolumn{17}{|c|}{ Kids' section of menu boards } \\
\hline Total§ & 1063 & 738 & $62 \cdot 2$ & 0.4 & $66 \cdot 2^{*}$ & 0.5 & $6 \cdot 0^{*}, \mathbb{\Upsilon}$ & 0.5 & 1125 & 738 & $221 \cdot 3$ & 4.5 & $172 \cdot 1^{*}$ & $4 \cdot 7$ & $-57 \cdot 9^{*}, \mathbb{\emptyset}$ & $5 \cdot 7$ \\
\hline Foods & 591 & 485 & 55.5 & 0.5 & $62 \cdot 5^{*}$ & 0.7 & $6 \cdot 7^{*}$ & 0.8 & 653 & 485 & 278.9 & 6.5 & $205 \cdot 3^{*}$ & $6 \cdot 7$ & $-74 \cdot 7^{*}$ & 8.6 \\
\hline Beverages\| & 472 & 253 & $70 \cdot 6$ & 0.1 & $73 \cdot 2^{*}$ & 0.2 & $3 \cdot 6^{*}$ & 0.2 & 472 & 253 & 141.6 & 3.3 & $108 \cdot 5^{\star}$ & 1.5 & $-33 \cdot 6^{\star}$ & 2.9 \\
\hline \multicolumn{17}{|l|}{ Any signs } \\
\hline Total§ & 2177 & 2421 & $54 \cdot 2$ & 0.3 & 54.5 & 0.3 & $2 \cdot 2^{*}, \mathbb{\prod}$ & 0.4 & 2177 & 2441 & 388.3 & 5.6 & 382.5 & 4.7 & $-33 \cdot 5^{\star}, \mathbb{\prod}$ & $5 \cdot 8$ \\
\hline Foods $\|$ & 1536 & 1962 & 47.9 & 0.3 & $51 \cdot 5^{\star}$ & 0.3 & $3 \cdot 4^{*}$ & 0.5 & 1536 & 1962 & 497.0 & 5.8 & $426 \cdot 3^{*}$ & $5 \cdot 0$ & $-66 \cdot 4^{*}$ & $7 \cdot 1$ \\
\hline Beverages $\|$ & 641 & 459 & $69 \cdot 2$ & 0.1 & $67.4^{*}$ & 0.2 & $-1 \cdot 8^{*}$ & 0.2 & 641 & 479 & $127 \cdot 8$ & 3.5 & $202 \cdot 8^{*}$ & 8.2 & $75 \cdot 9^{\star}$ & $6 \cdot 4$ \\
\hline
\end{tabular}

$\mathrm{NPI}$ is an overall nutritional quality score based on energy, sodium, saturated fat, sugar, protein and fibre ${ }^{(26)}$; scores range from 0 (poorest nutritional quality) to 100 (highest nutritional quality).

To convert energy to kJ, multiply kcal values by $4 \cdot 184$.

*Indicates significant differences between 2010 and 2013 at $P<0.05$.

$\dagger N$ represents the total number of times that items in each category were marketed across all stores.

$\ddagger N$ for total energy is not always the same as $N$ for NPI scores for the same year due to missing serving size information for some of the items, which is required to calculate NPI scores.

§Adjusted effects are adjusted for food or beverage and restaurant chain.

$\|$ Adjusted effects are adjusted for restaurant chain.

TIndicates that the interaction term between time and food or beverage was significant in adjusted models. 
Table 2 Linear regression showing changes in Nutrient Profile Index scores (NPI) and total energy from 2010 to 2013 for foods and beverages marketed on menu boards and signs at McDonald's (100 locations in the USA)

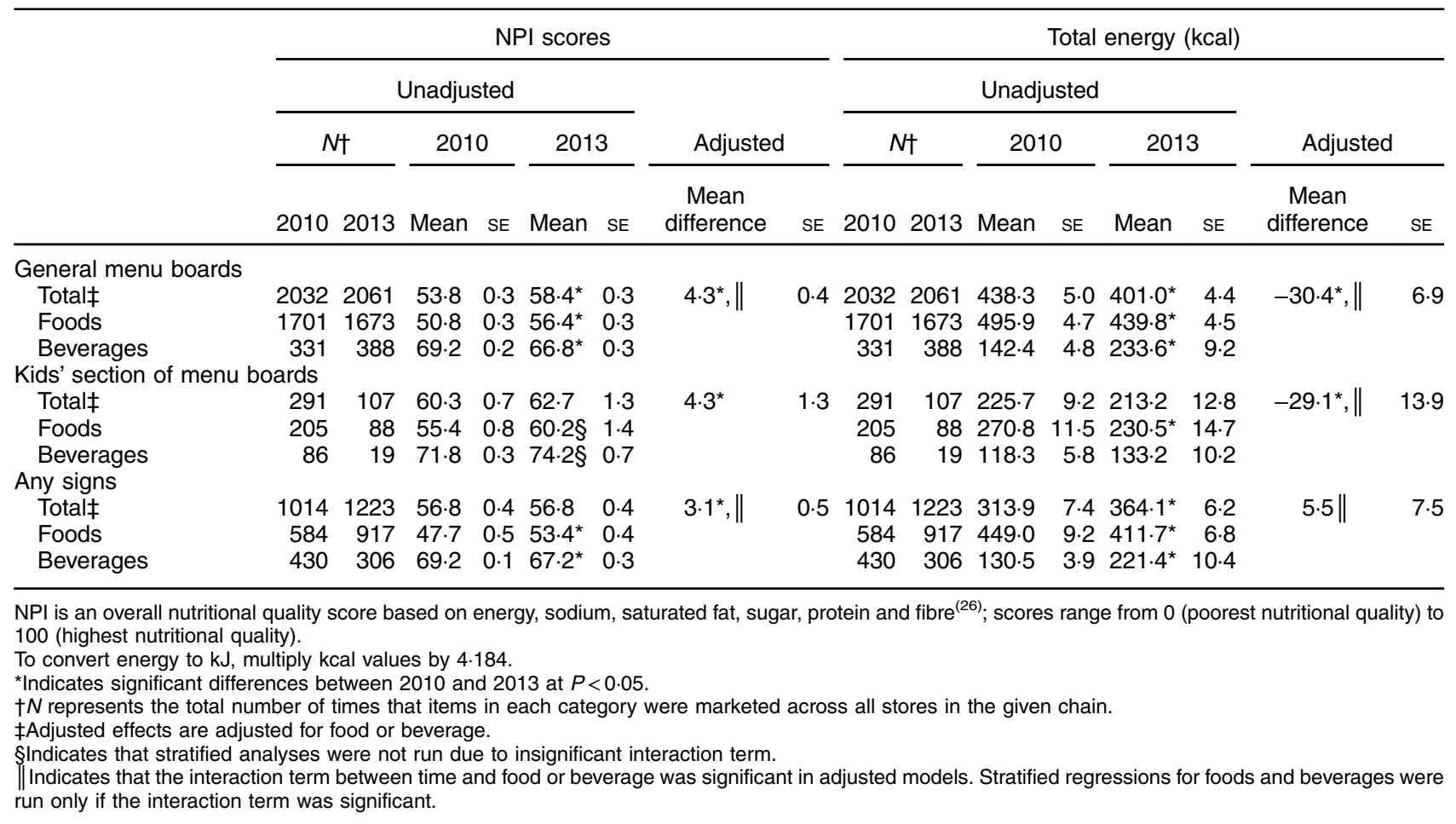

Table 3 Linear regression showing changes in Nutrient Profile Index (NPI) scores and total energy from 2010 to 2013 for foods and beverages marketed on menu boards and signs at Burger King (100 locations in the USA)

\begin{tabular}{|c|c|c|c|c|c|c|c|c|c|c|c|c|c|c|c|c|}
\hline & \multicolumn{8}{|c|}{ NPI scores } & \multicolumn{8}{|c|}{ Total energy (kcal) } \\
\hline & \multicolumn{6}{|c|}{ Unadjusted } & & & \multicolumn{6}{|c|}{ Unadjusted } & \multirow{2}{*}{\multicolumn{2}{|c|}{ Adjusted }} \\
\hline & \multicolumn{2}{|c|}{$N+$} & \multicolumn{2}{|c|}{2010} & \multicolumn{2}{|c|}{2013} & \multicolumn{2}{|l|}{ Adjusted } & \multicolumn{2}{|c|}{$N \uparrow, \ddagger$} & \multicolumn{2}{|c|}{2010} & \multicolumn{2}{|c|}{2013} & & \\
\hline & 2010 & 2013 & Mean & SE & Mean & SE & $\begin{array}{c}\text { Mean } \\
\text { difference }\end{array}$ & SE & 2010 & 2013 & Mean & SE & Mean & SE & $\begin{array}{c}\text { Mean } \\
\text { difference }\end{array}$ & SE \\
\hline \multicolumn{17}{|c|}{ General menu boards } \\
\hline Total§ & 1963 & 2085 & $53 \cdot 8$ & 0.3 & $55 \cdot 6^{*}$ & 0.3 & $1 \cdot 8^{*}, \|$ & 0.2 & 1963 & 2150 & $512 \cdot 9$ & $6 \cdot 7$ & $435 \cdot 3^{*}$ & $5 \cdot 1$ & $-68 \cdot 4^{*}, \|$ & $6 \cdot 4$ \\
\hline Foods & 1579 & 1679 & $50 \cdot 1$ & 0.3 & $52 \cdot 6^{*}$ & 0.3 & & & 1579 & 1679 & $606 \cdot 3$ & $6 \cdot 3$ & $504.9^{*}$ & 4.9 & & \\
\hline Beverages & 384 & 406 & 69.3 & 0.1 & $67 \cdot 8^{*}$ & 0.2 & & & 384 & 471 & 128.9 & $6 \cdot 4$ & $187 \cdot 5^{\star}$ & $7 \cdot 3$ & & \\
\hline \multicolumn{17}{|c|}{ Kids' section of menu boards } \\
\hline Total§ & 366 & 195 & $66 \cdot 2$ & 0.6 & $67 \cdot 2$ & 0.8 & $6 \cdot 2^{*}, \|$ & $1 \cdot 2$ & 366 & 195 & 202.9 & $8 \cdot 2$ & 217.9 & $12 \cdot 7$ & $-44 \cdot 1^{*}$ & $12 \cdot 4$ \\
\hline Foods & 157 & 173 & $59 \cdot 2$ & 1.0 & $66 \cdot 3^{*}$ & 0.9 & & & 157 & 173 & 278.9 & $15 \cdot 4$ & 230.5 I & 14.0 & & \\
\hline Beverages & 209 & 22 & 71.6 & 0.2 & $73 \cdot 6^{*}$ & 0.5 & & & 209 & 22 & $145 \cdot 9$ & $6 \cdot 0$ & $119 \cdot 1 \rrbracket$ & 5.9 & & \\
\hline \multicolumn{17}{|l|}{ Any signs } \\
\hline Total§ & 1163 & 1198 & 51.9 & 0.4 & $52 \cdot 1$ & 0.4 & $1 \cdot 3^{*}, \|$ & 0.5 & 1163 & 1218 & $453 \cdot 1$ & $7 \cdot 7$ & $400 \cdot 9^{*}$ & $7 \cdot 0$ & $-65 \cdot 6^{*}, \|$ & $7 \cdot 8$ \\
\hline Foods & 952 & 1045 & $48 \cdot 1$ & 0.4 & $49 \cdot 8^{*}$ & 0.5 & & & 952 & 1045 & 526.4 & $7 \cdot 3$ & $439 \cdot 1^{*}$ & $7 \cdot 3$ & & \\
\hline Beverages & 211 & 153 & $69 \cdot 2$ & 0.1 & $67.9^{*}$ & 0.3 & & & 211 & 173 & $122 \cdot 3$ & $7 \cdot 3$ & $169 \cdot 9^{*}$ & $12 \cdot 8$ & & \\
\hline
\end{tabular}

$\mathrm{NPI}$ is an overall nutritional quality score based on energy, sodium, saturated fat, sugar, protein and fibre ${ }^{(26)}$; scores range from 0 (poorest nutritional quality) to 100 (highest nutritional quality).

To convert energy to $\mathrm{kJ}$, multiply kcal values by $4 \cdot 184$.

*Indicates significant differences between 2010 and 2013 at $P<0.05$

$\dagger N$ represents the total number of times that items in each category were marketed across all stores in the given chain.

$\ddagger N$ for total energy is not always the same as $N$ for NPI scores for the same year due to missing serving size information for some of the items, which is required to calculate NPI scores.

§Adjusted effects are adjusted for food or beverage.

$\|$ Indicates that the interaction term between time and food or beverage was significant in adjusted models. Stratified regressions for foods and beverages were run only if the interaction term was significant.

IIndicates that stratified analyses were not run due to insignificant interaction term. 
Table 4 Linear regression showing changes in Nutrient Profile Index (NPI) scores and total energy from 2010 to 2013 for foods and beverages marketed on menu boards and signs, at Wendy's and Taco Bell (100 locations per chain in the USA)

\begin{tabular}{|c|c|c|c|c|c|c|c|c|c|c|c|c|c|c|c|c|}
\hline & \multicolumn{8}{|c|}{ NPI scores } & \multicolumn{8}{|c|}{ Total energy (kcal) } \\
\hline & \multicolumn{6}{|c|}{ Unadjusted } & & & \multicolumn{6}{|c|}{ Unadjusted } & \multirow{2}{*}{\multicolumn{2}{|c|}{ Adjusted }} \\
\hline & \multicolumn{2}{|c|}{$N \dagger$} & \multicolumn{2}{|c|}{2010} & \multicolumn{2}{|c|}{2013} & \multicolumn{2}{|c|}{ Adjusted } & \multicolumn{2}{|c|}{$N+, \ddagger$} & \multicolumn{2}{|c|}{2010} & \multicolumn{2}{|c|}{2013} & & \\
\hline & 2010 & 2013 & Mean & SE & Mean & SE & $\begin{array}{c}\text { Mean } \\
\text { difference }\end{array}$ & SE & 2010 & 2013 & Mean & SE & Mean & SE & $\begin{array}{c}\text { Mean } \\
\text { difference }\end{array}$ & SE \\
\hline \multicolumn{17}{|c|}{ Wendy's: general menu boards } \\
\hline Total§ & 2007 & 829 & $55 \cdot 5$ & 0.3 & $59 \cdot 1^{*}$ & 0.4 & $2 \cdot 3^{*},{ }^{* *}$ & 0.4 & 2045 & 895 & $507 \cdot 9$ & $5 \cdot 9$ & $427 \cdot 1^{*}$ & 7.9 & $-42 \cdot 3^{*},{ }^{* *}$ & $9 \cdot 0$ \\
\hline Foods & 1839 & 673 & 54.4 & 0.3 & $57 \cdot 1^{*}$ & 0.5 & & & 1877 & 731 & 541.4 & $5 \cdot 8$ & $491 \cdot 1^{*}$ & $7 \cdot 7$ & & \\
\hline Beverages & 168 & 156 & 68.0 & 0.2 & $68 \cdot 1$ & 0.2 & & & 168 & 164 & 132.9 & 6.8 & 141.6 & 8.5 & & \\
\hline \multicolumn{17}{|c|}{ Wendy's $\|$ : kids' section of menu boards } \\
\hline Total§ & 406 & 436 & $60 \cdot 0$ & 0.6 & $66 \cdot 6^{*}$ & 0.7 & $5 \cdot 9^{*}, * *$ & 0.7 & 468 & 436 & 232.9 & 6.5 & $141 \cdot 5^{\star}$ & $4 \cdot 1$ & $-80 \cdot 2^{*},{ }^{\star *}$ & 7.5 \\
\hline Foods & 229 & 224 & $53 \cdot 0$ & 0.8 & $60 \cdot 4^{*}$ & $1 \cdot 2$ & & & 291 & 224 & 284.6 & 8.8 & $175 \cdot 9^{*}$ & $7 \cdot 1$ & & \\
\hline Beverages & 177 & 212 & $69 \cdot 0$ & 0.2 & $73 \cdot 1^{*}$ & 0.2 & & & 177 & 212 & $148 \cdot 0$ & $4 \cdot 1$ & $105 \cdot 2^{*}$ & $1 \cdot 3$ & & \\
\hline \multicolumn{17}{|c|}{ Taco Bell|ף: general menu boards } \\
\hline Total§ & 1556 & 2472 & $60 \cdot 2$ & 0.3 & $63 \cdot 1^{*}$ & 0.2 & $3 \cdot 3^{*}$, ,* & 0.2 & 1556 & 2472 & 373.7 & 4.9 & $411 \cdot 8^{*}$ & 4.2 & $24 \cdot 5^{\star}$ & 4.6 \\
\hline Foods & 1319 & 2236 & 58.9 & 0.3 & $62 \cdot 7^{*}$ & 0.2 & & & 1319 & 2236 & 410.2 & 5.0 & $434.6 \dagger \dagger$ & 4.3 & & \\
\hline Beverages & 237 & 236 & 67.5 & 0.1 & $67 \cdot 0^{\star}$ & 0.1 & & & 237 & 236 & $170 \cdot 3$ & 7.8 & $195.4 \dagger \dagger$ & 6.6 & & \\
\hline
\end{tabular}

$\mathrm{NPI}$ is an overall nutritional quality score based on energy, sodium, saturated fat, sugar, protein and fibre ${ }^{(26)}$; scores range from 0 (poorest nutritional quality) to 100 (highest nutritional quality).

To convert energy to kJ, multiply kcal values by 4.184.

*Indicates significant differences between 2010 and 2013 at $P<0.05$

$\dagger N$ represents the total number of times that items in each category were marketed across all stores in the given chain.

$\ddagger N$ for total energy is not always the same as $N$ for NPI scores for the same year due to missing serving size information for some of the items, which is required to calculate NPI scores.

$\S$ Adjusted effects are adjusted for food or beverage.

Wendy's was not included in the sign analysis due to missing data.

\Taco Bell was not included in the kids' menu board analysis because it discontinued its kids' menu in 2013 before data collection, nor in the sign analysis due to missing data.

**Indicates that the interaction term between time and food or beverage was significant in adjusted models. Stratified regressions for foods and beverages were run only if the interaction term was significant.

††Indicates that stratified analyses were not run due to insignificant interaction term.

The kids' section of menu boards

Across all four chains, pictured items on the kids' section of menu boards became significantly healthier over time, increasing in NPI scores and decreasing in energy in adjusted analyses (Table 1). Although both pictured foods and beverages improved in nutritional quality over time and the interaction with time for both categories was significant for NPI scores $(P=0.008)$ and energy $(P<0 \cdot 001)$, foods had larger improvements than beverages $(P<0.001$ for both stratified models). However, in 2013, pictured foods on the kids' section of menu boards still did not meet the cut-off designating 'healthier' foods (mean NPI score 62.5 (SE 0.7)), while beverages did (mean NPI score $73 \cdot 2$ (SE 0.2)).

An identical pattern was observed for Wendy's (Table 4). For McDonald's (Table 2), although there was no significant interaction between time and food or beverage when examining NPI scores $(P=0 \cdot 174)$, a significant interaction for energy $(P=0.003)$ revealed that only pictured foods decreased significantly in energy $(P=0.017)$, while beverages did not change $(P=0.070)$. Conversely, for Burger King (Table 3), the interaction between time and food or beverage was significant only for NPI scores $(P<0.001)$, with foods showing larger improvements in NPI scores (difference $=7.19 ; P<0.001$ ) than beverages (difference $=2.08 ; \quad P<0.001$ ); there was no significant difference for energy $(P=0 \cdot 184)$.
Signs

Total featured items on signs became significantly healthier over time based on both nutrition outcomes in adjusted analyses (Table 1). However, the interaction between time and food or beverage was significant for both NPI scores and energy $(P<0 \cdot 001)$. Although featured foods became significantly healthier over time $(P<0 \cdot 001$ for NPI scores and energy), beverages became significantly less healthy $(P<0.001$ for NPI scores and energy). Neither foods nor beverages met the NPI cut-offs designating 'healthier' items.

An identical pattern held for Burger King (Table 3). For McDonald's (Table 2), total featured items increased significantly in NPI score, but did not change in energy. An identical pattern for the interaction held, with featured foods becoming healthier over time $(P<0.001$ for NPI scores and energy) and beverages becoming less healthy $(P<0.001$ for NPI scores and energy).

\section{Comparing marketing practices across restaurant chains in 2013}

General menu boards

In 2013, after adjusting for food or beverage, there were significant differences across chains in both NPI scores 
(a)

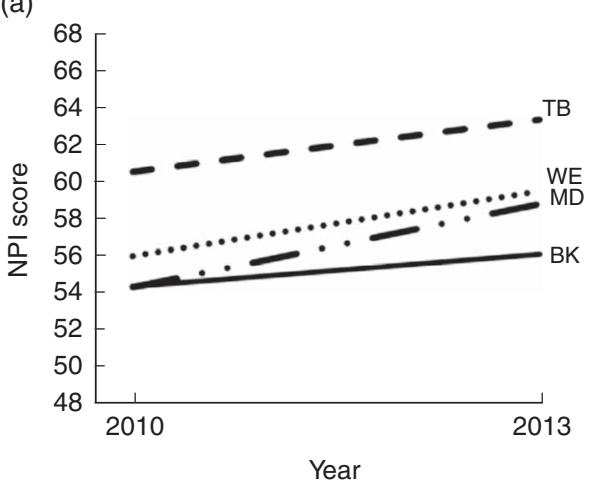

(c)

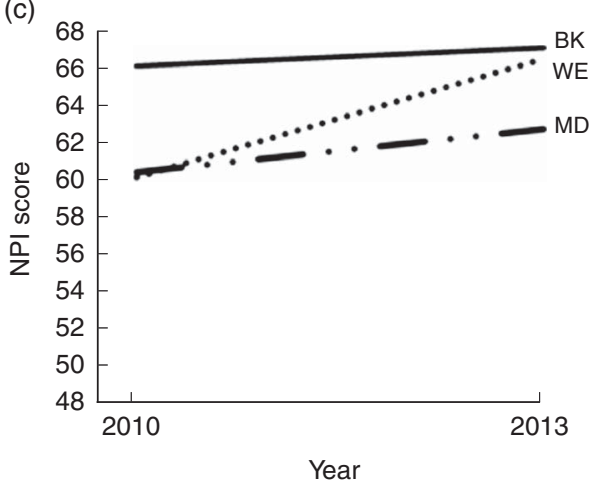

(e)

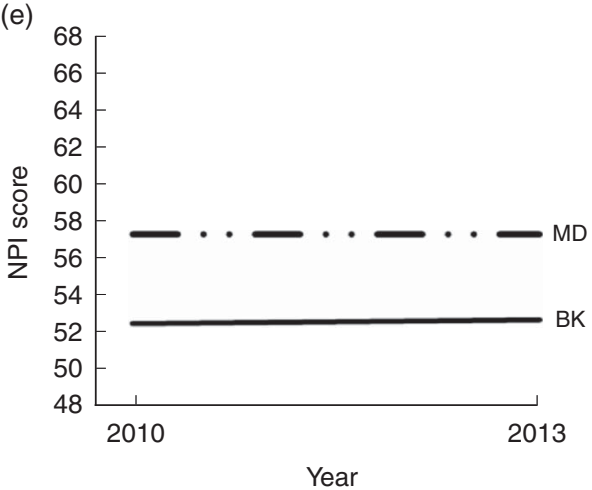

(b)

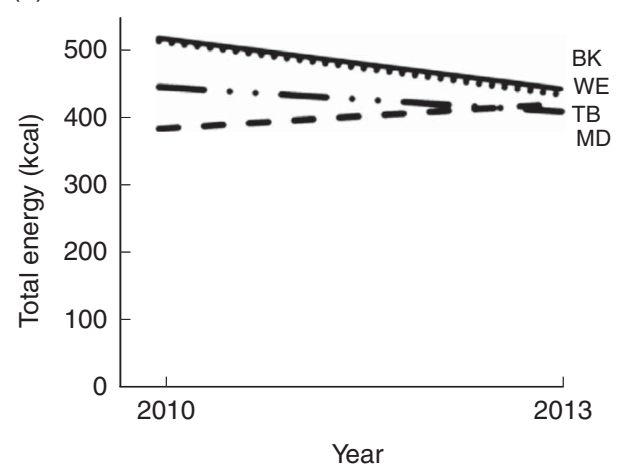

(d)

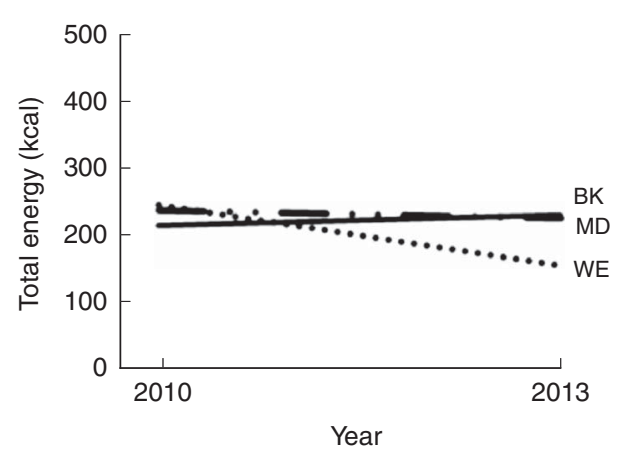

(f)

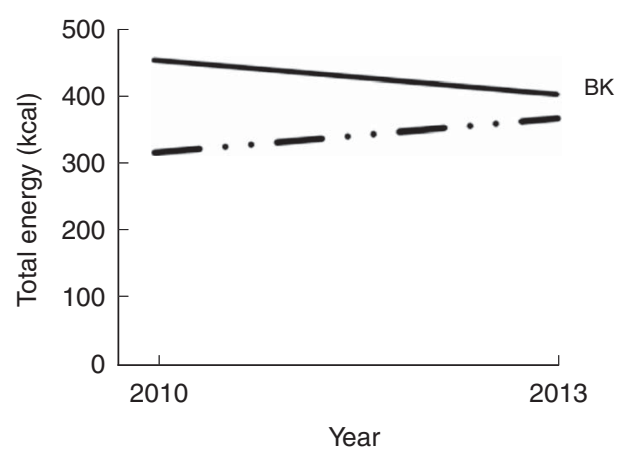

Fig. 1 Change in mean Nutrient Profile Index (NPI) scores (a, c, e) and energy (b, d, f) from 2010 to 2013 in all menu items marketed on general menu boards $(a, b)$, the kids' section of menu boards (c, d) and signs (e, f) in four major (US) fast-food restaurant chains (100 locations per chain: - .. - McDonald's (MD); — , Burger King (BK); …...., Wendy's (WE); - —, Taco Bell (TB)). NPI is an overall nutritional quality score based on energy, sodium, saturated fat, sugar, protein and fibre ${ }^{(26)}$; scores range from 0 (poorest nutritional quality) to 100 (highest nutritional quality). Values plotted represent unadjusted mean NPI scores and energy (to convert to kJ, multiply kcal values by 4.184), but restaurant abbreviations in plots denote chains where mean differences across time were significant (at $P<0.05)$ in adjusted analyses. Taco Bell was not included in the kids' menu board analysis (c, d) because it discontinued its kids' menu in 2013 before data collection. Wendy's and Taco Bell were not included in the sign analysis $(e, f)$ due to missing data.

and total energy of pictured items on general menu boards $(P<0.001$ for both outcomes). Taco Bell had the healthiest mean NPI score for pictured items, while Burger King had the worst, and both Taco Bell and Burger King differed significantly from each of the other chains $(P<0 \cdot 001)$. Items pictured at Burger King and Wendy's also had significantly higher mean energy than at Taco Bell $(P<0 \cdot 001)$ and McDonald's $(P<0.001$ for Burger King and $P=0.002$ for Wendy's).
The kids' section of menu boards

Restaurants differed significantly in NPI scores and energy amounts $(P<0 \cdot 001)$ of pictured items on the kids' section of menu boards. Items pictured at Burger King had significantly higher mean NPI scores than those at McDonald's and Wendy's $(P<0.001)$, after adjusting for food or beverage. However, items pictured at Wendy's had the lowest mean energy, which differed significantly from the other two chains $(P<0.001)$. 


\section{Signs}

In 2013, featured items on signs at McDonald's were significantly healthier than at Burger King, with higher NPI scores $(P<0 \cdot 001)$ and lower energy $(P=0 \cdot 041)$.

\section{Changes in proportions of featured items that were 'bealthier' on menu boards and signs}

Overall, the proportion of pictured items that met the 'healthier' cut-off increased from 2010 to 2013 on general menu boards $(33.9 \%$ in 2010 to $47.2 \%$ in $2013, P<0.001$ ) and all four chains demonstrated similar increases (see online supplementary material, Fig. S1). The proportion of pictured items meeting the 'healthier' cut-off on kids' menu boards also increased from $50.8 \%$ to $62.3 \%$ $(P<0 \cdot 001)$, but this was driven by increases in the proportion of 'healthier' items at Wendy's $(P<0.001)$, while the corresponding proportion decreased at Burger King (64.5\% in 2010 to $50.8 \%$ in $2013, P<0.001)$ and did not change at McDonald's. Overall, the proportion of 'healthier' items on signs also increased $(27.5 \%$ to $32.0 \%$, $P=0.001)$. This was driven by significant increases in the proportion of 'healthier' items featured at Burger King (23.3\% in 2010 to $28.5 \%$ in $2013, P=0.001)$, as there were no changes at McDonald's $(P=0 \cdot 118$; see online supplementary material, Table S1).

\section{Discussion}

Items pictured on general menu boards and featured on signs of four major fast-food chains remained at poor nutritional levels in 2013, despite modest improvements in average nutritional quality and declines in average energy in 2013 compared with 2010. Despite small improvements, these marketed items, on average, remained below the NPI cut-offs for healthier products for each of the chains. The small observed improvements on general menu boards and signs were primarily driven by featured foods, as the nutritional quality of featured beverages worsened over time at McDonald's, Burger King and Taco Bell, and remained unchanged at Wendy's.

On the kids' section of menu boards, results suggest that pictured items showed the most consistent improvements for both foods and beverages. For Burger King and Wendy's, these improvements were of a larger magnitude compared with those seen on general menu boards or signs, but no formal statistical tests were conducted to compare changes on the kids' section of the menu boards $v$. general menu boards or signage between chains. Although beverages pictured on general menu boards and featured on signs often declined in average nutritional quality, the kids' section of menu boards pictured healthier beverages over time. Furthermore, in 2013 the mean NPI scores of foods at Burger King and of beverages at all three chains in the kids' menu board analysis exceeded the cutoffs signifying healthier items. Finally, on general and kids' menu boards and signs, the proportion of healthier marketed items increased in 2013 compared with 2010, with the largest proportions of healthier items occurring on the kids' section of menu boards at both years.

The finding that pictured beverages on the kids' section of menu boards became healthier over time pre-dates pledges made in 2014 by McDonald's, Burger King and Wendy's to remove soda from their children's meals ${ }^{(36)}$. Even in advance of such pledges, the total number of beverages shown on the kids' section of menu boards at McDonald's and Burger King dropped considerably from 2010 to 2013 (from eighty-six to nineteen in McDonald's; from 209 to twenty-two in Burger King). Furthermore, in all three chains, only milk (flavoured or plain) or juice were pictured on the kids' section of menu boards in 2013 , whereas in 2010 sodas (non-diet and diet) and other sweetened fruit drinks were also shown. More recent data are needed to determine whether further improvements in marketing have been made in the light of recent pledges to remove soda.

The self-regulatory efforts by the fast-food industry to promote more nutritious choices, especially for children, must be evaluated with the limitations of these pledges in mind. Although Burger King and McDonald's are members of the CFBAI, which includes many of the nation's largest food and beverage companies and which aims to improve the quality of foods advertised to children ${ }^{(37)}$, these pledges do not cover marketing at restaurants. The voluntary decision by McDonald's to post energy information on menu boards may also reflect a shift towards greater transparency ${ }^{(22)}$. Some research on voluntary energy labelling has shown that it may encourage restaurants to introduce menu items with lower energy content ${ }^{(38)}$, while other work has indicated that restaurants also simply add more high-energy items as well ${ }^{(26)}$.

Taken together, these results suggest that restaurants have made only modest improvements in the nutritional quality of the foods they actively promote at restaurants, despite their public pledges. Furthermore, despite these small improvements, marketed foods and beverages in 2013 were, on average, still below the 'healthier' cut-offs, especially those shown on general menu boards or signage. Another study, which evaluated the nutritional quality of all foods and beverages offered on kids' menus at forty-five chain restaurants in the USA, found no meaningful improvements in average energy, saturated fat and sodium content between 2012 and 2015. Furthermore, restaurants participating in the industry's self-regulatory Kids LiveWell programme did not have healthier kids' menus, suggesting minimal effects of the programme ${ }^{(39)}$. The results of the present study also raise an additional concern that McDonald's and Burger King appear to be promoting beverages with more energy over time. Also at Taco Bell, both foods and beverages pictured on general menu boards showed significant increases in energy over time. There is still a clear need for improvement, especially 
given the low nutritional baseline of fast-food menu options found in the present study and elsewhere ${ }^{(40)}$.

Research has suggested that even after the CFBAI was created, children still continued to see many advertisements for nutritionally poor foods on television and their exposure to fast-food advertisements in particular has increased $^{(41)}$. Furthermore, in a study examining television advertisements from McDonald's and Burger King, even after their self-regulation pledges, children recalled toy premiums and cross-promotions more frequently than healthy foods and were still more likely to recall food items other than apples or milk ${ }^{(42)}$. This suggests that if unhealthy items on the kids' section of menu boards are pictured with toys or movie characters, children could still be drawn to the unhealthiest offerings, despite any improvements in the nutrition of pictured items. Finally, Taco Bell's removal of its kids' menu might lead to more children ordering adult portion sizes. Future research should also examine whether the chain might continue to market heavily to children on signs, despite having no kids' menu.

The current research has some limitations. Despite the ability to analyse changes over time, data were available from only two time points, ending in 2013. Future research should examine longer-term and current trends in fastfood marketing and promotion at restaurants in the light of industry pledges and soon-to-be-implemented energy labelling legislation. In addition, the present study did not examine the nutritional quality of children's meals that come with toys, a common marketing strategy that can influence children's meal choices. Another limitation is that the sample of restaurants at each time point differed. Even though restaurants were randomly selected within market areas in each year, differences in sampling between years could nevertheless affect results. In addition, we used the nutrition information provided by restaurants, which may have some inaccuracies ${ }^{(43)}$. However, research has shown that such inconsistencies are reduced when averaging across all foods together, as we have done in our study, compared with looking at individual items. An additional limitation is that the nutrient profiling model we used focuses largely on the contribution of individual nutrients to determine a nutritional quality score and does not take account of other important nutritional aspects such as percentage of whole grains. Finally, there was missing nutritional information on many items featured on signs because signs typically feature limitedtime or special-promotion items that are not included on restaurant websites. This restricted the analysis to only two chains, thereby limiting the generalizability of these findings. Furthermore, in all analyses, items with missing nutritional information were excluded; although such items made up less than $10 \%$ of the total data, their exclusion could nevertheless bias results if items with missing nutritional information were systematically more or less healthy than items with this information.
The present study also has a number of strengths. It is the first to date to focus specifically on the changes in nutritional quality of foods and beverages promoted instore in fast-food restaurants over time. A large sample of four of the nation's major fast-food chains was studied and items pictured on menu boards as well as those featured on signs were comprehensively evaluated within and on the exterior of stores. Finally, data were collected at the same time during each year, ensuring comparability across time.

\section{Conclusion}

In conclusion, the present study found modest improvements in the nutritional quality of menu items promoted at the point of purchase across four major fast-food chains in the USA, with the greatest improvements for the kids' section of menu boards. Although improvements were found for foods pictured on general menu boards and featured on signs, the nutritional quality of marketed beverages declined or remained unchanged in all chains. Despite limited improvements, marketed items nevertheless were on average of poor nutritional quality in 2013. In addition, items pictured on general menu boards in Taco Bell increased in energy. These findings highlight that fast-food restaurants still have ample opportunity to market healthier foods and beverages at stores.

\section{Acknowledgements}

Financial support: C.A.R. is supported by the National Institute on Aging of the National Institutes of Health (NIH) (award number P30AG034546). The content of this article is solely the responsibility of the authors and does not necessarily represent the official views of NIH. The National Institute on Aging of NIH had no role in the design, analysis or writing of this article. Conflict of interest: None. Authorship: J.S. formulated the research questions, analysed the data, drafted the initial manuscript and approved the final manuscript as submitted. J.L.H. provided the data, helped interpret the data, critically reviewed the manuscript and approved the final manuscript as submitted. K.K.D. and D.R.W. helped formulate the research questions and interpret the data, critically reviewed the manuscript and approved the final manuscript as submitted. C.A.R. contributed to formulating the research questions, helped interpret the data, critically reviewed the manuscript and approved the final manuscript as submitted. Ethics of human subject participation: Not applicable.

\section{Supplementary material}

To view supplementary material for this article, please visit https://doi.org/10.1017/S1368980018000629 


\section{References}

1. Bezerra IN, Curioni C \& Sichieri R (2012) Association between eating out of home and body weight. Nutr Rev 70, 65-79.

2. National Restaurant Association (2015) 2015 Restaurant Industry Pocket Factbook. http://www.restaurant.org/ Downloads/PDFs/News-Research/research/Factbook2015_ LetterSize-FINAL.pdf (accessed February 2016).

3. Paeratakul S, Ferdinand DP, Champagne CM et al. (2003) Fast-food consumption among US adults and children: dietary and nutrient intake profile. J Am Diet Assoc 103, 1332-1338.

4. Duffey KJ, Gordon-Larsen P, Steffen LM et al. (2009) Regular consumption from fast food establishments relative to other restaurants is differentially associated with metabolic outcomes in young adults. J Nutr 139, 2113-2118.

5. Powell LM \& Nguyen BT (2013) Fast-food and full-service restaurant consumption among children and adolescents: effect on energy, beverage, and nutrient intake. JAMA Pediatr 167, 14-20.

6. Harris JL, Schwartz MB, Brownell KD et al. (2010) Fast Food FACTS: Evaluating Fast Food Nutrition and Marketing to Youth. New Haven, CT: Yale Rudd Center for Food Policy \& Obesity.

7. Andreyeva T, Kelly IR \& Harris JL (2011) Exposure to food advertising on television: associations with children's fast food and soft drink consumption and obesity. Econ Hum Biol 9, 221-233.

8. Scully M, Dixon H \& Wakefield M (2009) Association between commercial television exposure and fast-food consumption among adults. Public Health Nutr 12, 105-110.

9. Swinburn BA, Sacks G, Hall KD et al. (2011) The global obesity pandemic: shaped by global drivers and local environments. Lancet 378, 804-814.

10. Buijzen M, Schuurman J \& Bomhof E (2008) Associations between children's television advertising exposure and their food consumption patterns: a household diarysurvey study. Appetite 50, 231-239.

11. Harris JL, Bargh JA \& Brownell KD (2009) Priming effects of television food advertising on eating behavior. Health Psychol 28, 404-413.

12. McGinnis JM, Gootman JA \& Kraak VI (editors) (2006) Food Marketing to Children and Youth: Threat or Opportunity? Washington, DC: National Academies Press.

13. Lobstein T \& Dibb S (2005) Evidence of a possible link between obesogenic food advertising and child overweight. Obes Rev 6, 203-208.

14. Halford JCG, Gillespie J, Brown V et al. (2004) Effect of television advertisements for foods on food consumption in children. Appetite 42, 221-225.

15. Veerman JL, Beeck EFV, Barendregt JJ et al. (2009) By how much would limiting TV food advertising reduce childhood obesity? Eur J Public Health 19, 365-369.

16. Borzekowski DLG \& Robinson TN (2001) The 30-second effect: an experiment revealing the impact of television commercials on food preferences of preschoolers. J Am Diet Assoc 101, 42-46.

17. Grossman M, Tekin E \& Wada R (2012) Fast-Food Restaurant Advertising on Television and Its Influence on Youth Body Composition. IZA Discussion Paper no. 7099. Bonn: Institute for the Study of Labor.

18. McClure AC, Tanski SE, Gilbert-Diamond D et al. (2013) Receptivity to television fast-food restaurant marketing and obesity among US youth. Am J Prev Med 45, 560-568.

19. Chandon P, Hutchinson JW, Bradlow ET et al. (2009) Does in-store marketing work? Effects of the number and position of shelf facings on brand attention and evaluation at the point of purchase. $J$ Mark $\mathbf{7 3}, 1-17$.
20. Chandon P \& Wansink B (2007) The biasing health halos of fast-food restaurant health claims: lower calorie estimates and higher side-dish consumption intentions. J Consum Res 34, 301-314.

21. Powell LM, Rimkus LM, Isgor Z et al. (2012) Exterior Marketing Practices of Fast-Food Restaurants - A BTG Research Brief. Chicago, IL: Bridging the Gap Program, Health Policy Center, Institute for Health Research and Policy, University of Illinois at Chicago.

22. McDonald's Newsroom (2012) McDonald's USA adding calorie counts to menu boards, innovating with recommended food groups, publishes nutrition progress report. http://www.news.mcdonalds.com/US/releases/McDONALD $\%$ E2\%80\%99S-USA-ADDING-CALORIE-COUNTS-TO-MENUBOARD (accessed June 2014).

23. Gasparro A \& Warner M (2012) Burger King's new menu, marketing boost profit. The Wall Street Journal, 1 August 2012. http://www.wsj.com/articles/SB100008723963904436 87504577562770509811152 (accessed March 2018).

24. National Restaurant Association (n.d.) Kids LiveWell Program. http://www.restaurant.org/Industry-Impact/FoodHealthy-Living/Kids-LiveWell-Program (accessed December 2015).

25. Council of Better Business Bureaus, Inc. (n.d.) Children's Food and Beverage Advertising Initiative (CFBAI). http://www.bbb.org/council/the-national-partner-program/ national-advertising-review-services/childrens-food-andbeverage-advertising-initiative/about-the-initiative/ (accessed December 2015).

26. Harris JL, Schwartz MB, Munsell CR et al. (2013) Fast Food FACTS 2013: Measuring Progress in Nutrition and Marketing to Children and Teens. New Haven, CT: Yale Rudd Center for Food Policy \& Obesity.

27. Bernstein S (2011) Fast-food industry is quietly defeating Happy Meal bans. Los Angeles Times, 18 May 2011. http:// articles.latimes.com/2011/may/18/business/la-fi-happy-mealbacklash-20110518 (accessed March 2018).

28. Hobin EP, Hammond DG, Daniel S et al. (2012) The Happy $\mathrm{Meal}^{\circledR}$ effect: the impact of toy premiums on healthy eating among children in Ontario, Canada. Can J Public Health 103, e244-e248.

29. Cohen DA \& Babey SH (2012) Contextual influences on eating behaviours: heuristic processing and dietary choices. Obes Rev 13, 766-779.

30. QSR Magazine (2010) 2010 QSR 50. http://www.qsrmaga zine.com/reports/2010-qsr-50 (accessed December 2015).

31. OFCOM (2007) Television Advertising of Food and Drink Products to Children - Final Statement. http://www.ofcom. org.uk/consultations-and-statements/category-2/foodads_new/ statement (accessed June 2014)

32. Scarborough P, Rayner M, Stockley L et al. (2007) Nutrition professionals' perception of the 'healthiness' of individual foods. Public Health Nutr 10, 346-353.

33. Bragg MA, Liu PJ, Roberto CA et al. (2013) The use of sports references in marketing of food and beverage products in supermarkets. Public Health Nutr 16, 738-742.

34. Department of Health (2011) Nutrient Profiling Technical Guidance. http://www.gov.uk/government/uploads/system/ uploads/attachment_data/file/216094/dh_123492.pdf (accessed June 2017).

35. Rayner M, Scarborough P \& Lobstein T (2009) The UK Ofcom Nutrient Profiling Model: defining 'healthy' and 'unhealthy' foods and drinks for TV advertising to children. http://www.ndph.ox.ac.uk/cpnp/about/publications-andreports/group-reports/uk-ofcom-nutrient-profile-model.pdf (accessed June 2017).

36. Esterl M (2015) Dairy Queen orders sodas out of kids meals. The Wall Street Journal, 14 May 2015. http://www. wsj.com/articles/dairy-queen-orders-sodas-out-of-kids-meals1431635689 (accessed March 2018). 
37. Kolish ED \& Peeler CL (2008) Changing the Landscape of Food \& Beverage Advertising: The Children's Food \& Beverage Advertising Initiative in Action - A Progress Report on the First Six Months of Implementation: JulyDecember 2007. Arlington, VA: Council of Better Business Bureaus, Inc.

38. Bleich SN, Wolfson JA, Jarlenski MP et al. (2015) Restaurants with calories displayed on menus had lower calorie counts compared to restaurants without such labels. Health Aff (Millwood) 34, 1877-1884.

39. Moran AJ, Block JP, Goshev SG et al. (2017) Trends in nutrient content of children's menu items in US chain restaurants. Am J Prev Med 52, 284-291.
40. Kirkpatrick SI, Reedy J, Kahle LL et al. (2014) Fast-food menu offerings vary in dietary quality, but are consistently poor. Public Health Nutr 17, 924-931.

41. Powell LM, Schermbeck RM, Szczypka G et al. (2011) Trends in the nutritional content of television food advertisements seen by children in the United States: analyses by age, food categories, and companies. Arch Pediatr Adolesc Med 165, 1078-1086.

42. Bernhardt AM, Wilking C, Gilbert-Diamond D et al. (2015) Children's recall of fast food television advertising - testing the adequacy of food marketing regulation. PLoS One 10, e0119300.

43. Urban LE, McCrory MA, Dallal GE et al. (2011) Accuracy of stated energy contents of restaurant foods. JAMA 306, 287-293. 